\title{
EL CAMINO QUE LLEVA A NATALIA GINZBURG: EL LESSICO FAMIGLIARE DESDE DENTRO
}

\author{
Juan Carlos de Miguel y Canuto \\ Universitat de València \\ Juan.C.Miguel@uv.es
}

\section{RESUMEN}

Recapitulación de algunas cuestiones críticas y ahondamiento en otras que se suscitan en torno a Lessico famigliare, la conocida obra de 1963. Se insiste en la dinámica interna del texto, en su evolución, atendiendo sobre todo a los fragmentos de la parte final. Se profundiza en el análisis del tiempo, demostrando cómo cuenta el acontecer histórico en el devenir familiar, principalmente en los años de la guerra y cómo la narradora refleja su transcurso. Se redefine el concepto mismo de «léxico familiar»y se hace ver la transformación de su funcionalidad dentro del relato.

Palabras Clave: Natalia Ginzburg, Lessico famigliare, narrativa, memoria, tiempo.

\section{ABSTRACT}

A review of some critical questions and a probing of others that arise from Lessico famigliare, the well known work of 1963. The internal dynamics and evolution of the text are stressed, with special attention given to the fragments of the final part. There is a particular analysis of time, showing how it narrates historical events through family history, especially during the period of war, and how the narrator reflects its passage. The concept of "family language" itself is redefined, and the changes in its function within the story are revealed.

KEY WORDS: Natalia Ginzburg, Lessico famigliare, narrative, memory, time. 
Nos acercamos a varias conmemoraciones en torno a Natalia Ginzburg: veinte años de su desaparición se han cumplido en 2011, cincuenta de la publicación de Lessico famigliare, su obra más leídas, se cumplirán en 2013, y cien de su nacimiento en 2016. Puede ser un momento oportuno para recapitular y repensar algunos juicios críticos, rindiendo justo homenaje a la autora.

La editorial Einaudi, radicada en Turín, ha sido una indudable columna vertebradora de la vida intelectual y literaria italiana de la segunda mitad del siglo XX. Su empuje cultural queda de manifiesto en su extenso y pujante catálogo, que es signo de una vitalidad que llega hasta nuestros días ${ }^{1}$. Surge en la década de los treinta y en sus albores estuvo ligada a la cultura antifascista y de la Resistencia. En su núcleo fundador se encuentran, junto al propio Giulio Einaudi, Leone Ginzburg y Cesare Pavese; posteriormente otros escritores, como Elio Vittorini y, más adelante, Italo Calvino serán enseñas y guías de la editorial. Una mujer de la casa, de toda la vida, fue Natalia Ginzburg, cuyo apellido de soltera era Levi. Allí trabajó y dejó su impronta durante mucho tiempo y allí publicó sus libros, aunque en los años setenta mediara un paréntesis de apartamiento voluntario ${ }^{2}$.

La strada che va in città, su primera novela, breve, la publicó con pseudónimo, para ocultar su apellido, inequívocamente hebreo, en 1942, en pleno torbellino fascista. Antes, en los años treinta, había editado relatos en revistas. Fue traductora de Proust. A lo largo del tiempo su escritura y su personalidad, muy acusadas, se hicieron bien reconocibles, por sus formas directas y esquemáticas, casi desnudas. Bajo una apariencia frecuente de humildad o de sermo vulgaris se esconde una elaborada técnica, en la que menos es más. En 1963, con la publicación de Lessico famigliare accedió al gran público; se transformó en una autora conocida y apreciada por los lectores. El libro ganó el reputado premio Strega de aquel año y a día de hoy sigue siendo la obra por excelencia que la identifica ${ }^{4}$. Escribió numerosos artículos periodísticos y ensayos, muchos de ellos reunidos en Le piccole virtù, de 1962, Mai devi domandarmi, de 1970 y en otros libros posteriores. Precisamente poco después del determinante éxito narrativo, empezó a componer y a estrenar obras teatrales (entre 1964 y 1991), que totalizarían casi una docena. La primera fue Ti ho sposato per allegria. Todas ellas, de tono chejoviano, están igualmente dotadas de una acusada identidad, sustanciada en la cháchara aparentemente fútil de los personajes, a menudo femeninos, que arrastra consigo una crónica interior sui generis.

\footnotetext{
${ }^{1}$ Más allá de que su configuración empresarial experimentase un gran cambio en los años ochenta.

${ }^{2}$ Cfr. Mangoni, 1999. Natalia Ginzburg había nacido en Palermo, en 1916, en cuya universidad estaba destinado como profesor su padre. Pertenecía a una familia de origen hebreo que se establecería en Turín. Se casó en 1938, pero pese a su temprana viudedad (Leone murió a los 35 años, en 1944) y posterior nuevo matrimonio (con el profesor Gabriele Baldini, en 1950, del que volvería a enviudar), firmó sus obras con el apellido de su primer marido, que era oriundo de Odesa. Tuvo cinco hijos, tres de su primer matrimonio y dos del segundo; de estos últimos la primera nació con una grave malformación y el segundo murió cuando contaba poco más de un año. En la década de los cuarenta militó en el Partito d'azione, de corte republicano y socialista, y más tarde -cuando este se había disuelto- en el Comunista, que abandonaría a principios de los cincuenta. Hacia el final de su vida llegó a ser elegida diputada en el parlamento durante dos legislaturas consecutivas, como independiente en las lista del PCI. Se declaraba hebrea y católica (Ginzburg, 1999: 65, 145 y 199). Era pesimista. Murió en Roma en 1991.

${ }^{3}$ Giovanelli (2005: 747) anota las virtudes de su escritura, que son: «la misura, la sobrietà e il pathos antiletterario».

${ }^{4}$ Algunos rasgos del L.F. se anticipan ya en Le voci della sera, la novela de 1961.
} 
Junto a las de Elsa Morante, Anna Maria Ortese, Lalla Romano y otras pocas, su escritura encarna lo mejor de lo aportado por mujeres a la literatura italiana en la segunda mitad del siglo. Aunque lo cierto es que a ella no le gustaba distinguir entre hombres y mujeres a la hora de valorar la escritura literaria ${ }^{5}$.

Precisamente en el año 1963 se crea en Italia, ligado a la revista boloñesa Il Verri, el llamado Gruppo ‘63, artífice de la conocida como «neovanguardia», un movimiento de renovación literaria drástica que apuesta por la ruptura con la tradición. En 1965 se efectuará el llamado «Congreso de Palermo» (el segundo) en el que se sentarán las bases programáticas de una propugnada novela experimental, cercana al nouveau roman. Pues bien, tan lejano se mantendrá el Lessico del ya superado neorrealismo, detestado por los componentes del Gruppo '63 y criticado por la misma Ginzburg (en el fragmento 39 del L.F.), como del entonces próximo experimentalismo. Su senda, de corte realista, será cada vez más individual y personal, ajena a corrientes dominantes.

Lessico famigliare ha excedido, con mucho, las veinte ediciones y el medio millón de ejemplares vendidos hasta hoy en Italia. Es una obra peculiar, que nace de la nostalgia. En ella, sin trastocar en absoluto las coordenadas de su escritura, su autora consiguió ganarse a las mayorías lectoras. El texto es un hito celebrativo de la familia, y concretamente de la familia de procedencia, y hasta tal punto ha calado en la mente de los italianos, que el marbete «léxico familiar» (un título lapidario, acertadísimo) se ha automatizado, se ha incorporado a la lengua común como una expresión cuyo significado remite directamente al contenido del libro. A partir de él numerosas personas han escrito o contado su propio "léxico familiar". Natalia Ginzburg, pues, supo dignificar, plasmándolo y rotulándolo, un extendido acervo oral, algunas de cuyas ocurrencias, las de su entorno inmediato, elevó a la categoría de material literario.

El relato reúne las notas habituales que identifican al género novela, excepto una, relevante: no es ficción. En una «Avvertenza» preliminar la autora nos revela que cuanto leeremos es la historia de una familia, la suya, y que nada ha sido inventado. Ha escrito solo «quello che ricordav[a]», aunque considera que se debe leer como si fuera una novela $^{6}$. Estamos, pues, ante una aventura de la memoria: una mujer que pertenece a una familia burguesa acomodada, culta, antifascista, socialista, en cuyo seno conoció a personajes relevantes de la vida pública, amigos de casa, decide contar su pasado, cuando la mayor parte de todo aquello es ya historia. Habla de los años de su infancia y juventud, llegando a los de su ser adulto, su maternidad, su viudez y sus segundas nupcias.

Pero lo notable es el punto de vista que articula todo ese bagaje. ¿Cómo engarzar ese enjambre de recuerdos, una materia con frecuencia dispersa y lábil? ¿Cómo contar? Pues, curiosamente, limitando su propia presencia y hablando mucho más de los otros, esta es la posición de la tímida autora-narradora, a menudo más testigo que protagonista, cuyo discurso en primera persona, no obstante, es el magma en el que se amalgaman todos

\footnotetext{
5 «Yo deseaba escribir como un hombre», (Ginzburg 1964).

${ }^{6}$ Esta declaración previa establece por parte del autor un auténtico "pacto con el lector" sui generis, esto es, unas condiciones de veracidad y unas premisas de lectura del texto particulares, que afectan también al género de la escritura. A partir de los años setenta del siglo XX, la crítica (la francesa especialmente) ha venido estudiando el amplio abanico discursivo de las escrituras del yo, desde la autobiografía hasta la denominada autoficción, y desarrollando toda una red conceptual propia (cfr. Lejeune, 1996). Indudablemente el LF, más allá del estudiado vínculo escritura-biográfica-femenina, se presta aún hoy a mayores indagaciones en ese campo.
} 
los materiales ajenos ${ }^{7}$ ¿ ¿Y cómo dosificar la información? Seleccionándola, sí, ordenándola, pero ¿con qué criterio? ¿Tal vez enfatizando lo más relevante para los lectores? Esto es, ¿concediendo más espacio a lo que ha conformado una dimensión colectiva, pública, o política, o bélica, que podría tener mayor interés social? Pues no. Lo que hace Natalia Ginzburg es dirigir el foco preferentemente hacia lo privado, dejando las graves noticias de los años 30 y 40 y sus protagonistas como telón de fondo; atender a vidas esencialmente privadas, renunciando a cualquier épica y conteniendo el relato de los dramas vividos, con una actitud que un crítico calificó de reservada a ultranza (cfr. Magrini 2007).

Y para ello decide dotarse de un instrumento sofisticado y muy simple a la vez. Recuperar, recrear, el "léxico familiar". Todo ese patrimonio oral formado por unas cuantas exclamaciones, denuestos, respuestas, expresiones, frases curiosas, inesperadas, llamativas en su contexto, que una serie de parientes y conocidos pronunció alguna vez, en alguna ocasión particular, y que desde entonces se han venido repitiendo, celebrando y chanceando, en familia. Muchas de ellas no están propiamente en lengua italiana sino que son dialectales, triestinas en diversas ocasiones, pues la familia Ginzburg era de origen triestino y en casa se escuchaban también vocablos milaneses, transmitidos por la madre, y otros de otras procedencias.

Ese, pues, es el Lessico famigliare, que caracteriza e identifica a tantos deudos y amigos, reduciéndolos al mismo tiempo a la mayoría de ellos a una dimensión modesta, como figuritas, marionetas parlantes. De esta manera, además del retrato de sus padres, de sus hermanos y de unos pocos amigos, en los que sí profundiza, la autora nos ofrece una galería amplísima de noticias y personajes, relacionados con los anteriores, que desfilan ante nuestros ojos, enriquecen la trama, distraen nuestra mente lectora con sus vicisitudes, excentricidades y ocurrencias y crean, a pesar de todo, un gran fresco, aunque parcial, de la sociedad italiana --la del norte más que nada- de los años del fascismo, de la guerra y la posguerra, principalmente. Pero un fresco de la vida intramuros. Intramuros de los hogares familiares.

De este modo, la empatía lograda con el lector es notable. La perspectiva de acercamiento a los personajes nos hace verlos en zapatillas y no vestidos de calle. Muchos de ellos son personajes sobresalientes en la vida civil, otros no, pero todos comparten la humanización que se deriva de conocer sus debilidades o, simplemente, de contemplarlos afrontando las mismas preocupaciones que los comunes mortales. Sin destacarlos especialmente en la actividad que los hizo célebres, sin ningún endiosamiento, sin ningún marco de plata. Es decir, los tenemos muy cerca de nosotros, tan a mano como nuestras propias vidas. Así, desfilan por las páginas del libro, entre otros, los socialistas Filippo Turati y Anna Kuliscioff, el comunista Giancarlo Pajetta, Carlo Rosselli (de Giustizia e libertà) y Ferruccio Parri (del Partito d'Azione), el empresario Adriano Olivetti y su padre -el fundador de la saga-, Vittorio Foa, político y sindicalista, Luigi Salvatorelli, historiador y periodista, Leo Pestelli, periodista y crítico, Franco Rasetti, físico, Luigi Einaudi «el editor», el filósofo Filippo Balbo, Carlo Levi y Cesare Pavese.

\footnotetext{
${ }^{7} \ll \mathrm{E}$ vi sono anche molte cose che pure ricordavo, e che ho tralasciato di scrivere; e fra queste, molte che mi riguardavano direttamente. Non avevo molta voglia di parlare di me. Questa di fatti non è la mia storia, ma piuttosto, [...] la storia della mia famiglia» (Avvertenza; Ginzburg 1986-1987).
} 
La figura del escritor y editor Cesare Pavese, amigo íntimo de Leone y después de Natalia, en la que influyó mucho ${ }^{8}$, está dibujada con trazos firmes y gran agudeza analítica (en los fragmentos 26, 32, 35 y 41). Son apuntes de la personalidad compleja y rebelde de un hombre joven que se nos aparece comiendo cerezas por la calle, a paso ligero, y estrellando los huesos contra los muros. Una persona seria, al principio despreocupada de la política y de tantas otras cosas, que se involucraba mucho en la escritura -la suya estaba muy ligada al ambiente turinés- y en el amor, cuyas desilusiones le sumían en un hondo sufrimiento. Dotado de una ironía que no ha quedado en sus libros -se nos dice- y lleno de temor por la guerra, incluso cuando esta había acabado (como la misma Natalia y tantos otros), su suicidio se presenta como fruto de un cálculo minucioso sobre la posteridad, la literatura y la memoria, por parte de alguien que no amaba suficientemente la vida9 .

La obra consta de cuarenta y siete fragmentos sucesivos (no numerados), de dimensiones muy desiguales ${ }^{10}$. Es una estructura bastante suelta, que aumenta la libertad de escritura de la autora respecto a otros modelos narrativos y le permite conducirse con flexibilidad, sin ser sistemática, con frecuentes saltos atrás y adelante en sus recuerdos, que conforman una historia que ella misma declara -en la Avvertenza- lagunosa. Al principio conocemos al padre, Giuseppe, a la madre, Lidia, a los cinco hijos (Gino, Mario, Alberto, Paola y Natalia) y a la criada Natalina. Los vemos en casa, en Turín, y haciendo senderismo por las cumbres piamontesas. Luego van desfilando por nuestra mente los abuelos y los amigos de la familia, los López, los Terni. Y los bisabuelos y los tíos maternos y paternos y otros parientes. Son gente de un estatus semejante a los Levi, y los cabezas de familia son a menudo profesores o científicos, como el señor Levi, o abogados.

Casi todos somos hijos de una familia y la mayoría hemos tenido hermanos (cierto es que ahora mayoritariamente se tienen menos que antes), por ello cuando leemos las primeras líneas de Lessico famigliare es difícil que no sonríamos con complicidad: las escenas que se producen en la mesa de la familia Levi, con ese padre gruñón, excéntrico y a menudo autoritario, corrigiendo y llamando al orden a sus hijos, recuerda en alguna medida a escenas domésticas vividas por muchos durante generaciones. Estos animados cuadros que incluyen los reniegos paternos, casi siempre en dialecto, inevitablemente pierden color y calor cuando se traducen a otras lenguas, como también otras expresiones características del léxico familiar.

Los primeros fragmentos del texto corresponden a la infancia y primera juventud de Natalia, que es la hija menor, bastante distanciada en edad de todos sus hermanos. La familia residía entonces en la calle Pastrengo y, cuando vaya pasando el tiempo y los hijos vayan abandonando el hogar familiar (lo que empieza a reflejarse a partir del fragmento 15) e incluso la familia cambie de domicilio (16), la madre se referirá con nostalgia a esos años como al «tempo di via Pastrengo». Y es que, visto con perspectiva, en conjunto, aquel fue un período feliz y, sobre todo, acabará formando un tiempo mítico: el pa-

\footnotetext{
${ }^{8}$ Según ella misma confiesa (Ginzburg 1999: 37).

${ }^{9}$ De gran intensidad poética es el conocido texto «Retrato de un amigo», recogido en Le piccole virtù. En esas páginas, en primera persona del plural, se ahonda en la compleja y hosca personalidad de Pavese, al que nunca se llega a nombrar, sin ahorrar elogios a sus virtudes ni críticas a sus limitaciones o defectos.

${ }^{10}$ Eran cuarenta y seis en las primeras ediciones, pero en la de la colección «I Meridiani», que asume una naturaleza canónica, en 1987, se produce una redistribución.
} 
radigma de la convivencia de todos juntos, bajo un mismo techo, en el templo del hogar, durante los cursos escolares y las vacaciones de verano, a las horas de comer y de cenar y en la sobremesa, en tiempos en que aún vivía la abuela paterna, cuando los amigos de la familia los visitaban, cuando la casa estaba poblada de gente que entraba y salía, cuando todos eran jóvenes y estaban llenos de ilusiones, cuando había un proyecto de futuro y una autoridad (la del padre) compartidos.

Ese tiempo mítico es el que parece haber calado más entre los lectores, el que más ha quedado en su memoria y al que la crítica igualmente parece haber prestado más atención, casi erigiéndolo en paradigma de todo el libro, que de alguna manera podría pasar por una suma de historias, personajes y anécdotas de tono un poco anecdótico. Pero las cosas no son exactamente así.

Acaso no se haya insistido bastante en el dinamismo del texto, en su evolución interna y en las diferencias de composición y tono según se avanza en la lectura ${ }^{11}$. El léxico familiar, el centón de frases pulidas por los años, es un barniz que recubre una materia no homogénea. Ni siquiera la coloquialidad de la lengua empleada, que a algunos -como al propio Montale- llegó a parecer casi excesiva, domina todo el texto por igual ${ }^{12}$. La autora evitó caer en un discurso demasiado serio o trascendente, sobre todo cuando los hechos narrados sí lo eran, así como en el sentimentalismo. Y en vez de dibujar personajes o historias acabadas prefirió esbozarlas, dejarlas entrever, tejerlas a medias, incluso resumirlas, pero sin cargar las tintas, permaneciendo ajena al patetismo y al prodigarse de la compasión. Volveremos sobre ello. Se ha de notar que, a la postre, esta contención sentimental de la escritura, al quedarse en el umbral de la sugerencia o la insinuación, resulta mucho más eficaz para el lector que el desbordamiento emotivo de lo explícito, que se arriesga siempre a caer en el exceso y en lo sentimentaloide.

Entre los citados fragmentos de la primera parte de la obra, hay uno, conocido, que es principal desde el punto de la comprensión interna del texto, de sus fundamentos. Se trata del cuarto; interesan especialmente de sus párrafos finales, éstos:

Noi siamo cinque fratelli. Abitiamo in città diverse, alcuni di noi stanno all'estero: e non ci scriviamo spesso. Quando c'incontriamo possiamo essere, l'uno com l'altro, indifferenti o distratti. Ma basta, fra noi, una parola. Basta una parola, una frase; una di quelle frasi antiche, sentite e ripetute infinite volte, nel tempo della nostra infanzia. [...] per ritrovare a un tratto i nostri antichi rapporti, e la nostra infanzia e giovinezza, legata indissolubilmente a quelle frasi, a quelle parole. Una di quelle frasi o parole, ci farebbe riconoscere l'uno con l'altro, noi fratelli, nel buio di una grotta, fra milioni di persone. Quelle frasi sono il nostro latino, il vocabolario dei nostri giorni andati, sono come i geroglifici degli egiziani o degli assiro-babilonesi, la testimonianza d'un nucleo vitale che ha cessato di esistere, ma che sopravvive nei suoi testi, salvati dalla furia delle acque, dalla corrosione del tempo. Quelle frasi sono il fondamento della nostra unità familiare, che sussisterà finché saremo al mondo.

\footnotetext{
${ }^{11}$ Carlo Prosperi apuntó algunas líneas en esta dirección: «Il romanzo non si ferma all'infanzia dell’autrice, il cui sguardo, via via che la storia procede, matura, acquista una nuova sensibilità» (Prosperi, 1996:66).

${ }^{12}$ El poeta, crítico y premio Nobel Eugenio Montale publicó una afortunada y conocida reseña, «Lessico famigliare crudele con dolcezza», en Il Corriere della sera del 17 de julio de 1963, de la que volveremos a ocuparnos.
} 
Así pues, lenguaje, identidad y memoria compartidos como base de supervivencia. Estas son las claves del entramado de la familia Levi y, por ende, del libro. Y no por casualidad el yo predominante en el enunciado ha dado paso a un nosotros. Con razón Cesare Garboli, agudo crítico y amigo íntimo de la autora (de la que fue uno de sus mayores intérpretes), ha hablado de «parole della tribù», para enfatizar la fuerza de la especie familiar $^{13}$. Y es que, con el transcurrir de los años, ese lenguaje llega a ser casi la ley única de la tribu, cuando todos son ya indudablemente adultos, la fuerte autoridad paterna ha declinado y los lazos familiares se han aflojado.

Pero en esos años dorados de la calle Pastrengo, especialmente valorados por la señora Levi y cantados por su hija menor, van fluyendo muchas informaciones que exceden al saber originario de Natalia: algunas se refieren a la intimidad de sus padres, otras a los abuelos y bisabuelos y a otros familiares lejanos. Estamos, pues, en el ámbito de los mecanismos de información y de las voces narrativas ${ }^{14}$. En la familia Levi hay una fuente que documenta y enriquece la trama, sin ella no habría relato, o este sería mucho más incompleto. Es Lidia, Lidia Tanzi, la madre que, curiosamente, asume también el patrimonio oral de su marido. Como bien recuerda la hija en el mismo fragmento citado:

Mio padre, lui, raccontava male, in modo confuso e sempre inframmezzando il racconto di quelle sue tuonanti risate, perché i ricordi della sua famiglia e della sua infanzia lo rallegravano; per cui di quei racconti spezzati da lunghe risate, noi non capivamo gran cosa.

Mia madre, invece, si rallegrava raccontando storie perché amava il piacere di raccontare.

Y a veces el padre protestaba por volver a oír historias ya conocidas, pero la madre no se cansaba de referir sus recuerdos a sus hijos. Es decir, que en su madre la autora encontró un primer germen de la literatura: el afán de contar historias. A este propósito hay otro fragmento clave. En él comprobamos cómo la materia contada por la madre, sus protagonistas, adquieren en la hija una dimensión de ensoñación, una consistencia mental, que se coloca ya en un plano distinto al de la realidad:

Turati e la Kuliscioff [...] si mescolavano, nella mia immaginazione, con altre figure anche esse sempre presenti nei ricordi di mi madre: i suoi genitori, il Silvio, il Demente, il Barbison. Persone o morte o comunque antichissime anche se vive ancora, perché partecipi di tempi lontani, di vicende remote, quando mia madre era piccola [...]; persone che non si potevano incontrare ora, che non si potevano toccare e che anche se si incontravano o si toccavano, non erano però le stesse di quando io le avevo pensate e che anche se vive ancora erano state tuttavia contagiate dalla vicinanza dei morti, con i quali abitavano nella mia anima: avevano preso, dei morti, il passo irragiungibile e leggero (Fragmento 9).

Todas estas personas, pues, en la mente de Natalia, tamizadas por el velo cierto o imaginario de la muerte habían cumplido ya el paso del universo real del ser al universo de la literatura: el mundo de la imaginación, de los sueños, de la alucinación o de la ficción, al

\footnotetext{
${ }^{13}$ Cesare Garboli ha escrito y publicado mucho sobre N. Ginzburg y sobre el L.F., en muchos lugares. Se deben mirar sus Introducciones a varias ediciones del texto, especialmente la de la obra, suelta, en la editorial Einaudi, y la de los dos volúmenes de la autora en la Mondadori, (Ginzburg 1986-1987).

${ }^{14}$ De la polifonía (bajtiniana) de esta novela ha tratado adecuadamente Barani (1990).
} 
que ya pertenecían, con más derecho que al otro. La Natalia niña no podía ser consciente de ello, pero muchos años más tarde la adulta no haría otra cosa que exteriorizar y cultivar la semilla que ya estaba sembrada en ella. Entonces nace la literatura.

Hay un movimiento de deslizamiento progresivo, perceptible dentro del Lessico, en virtud del cual la voz de Natalia se va emancipando paulatinamente de la influencia materna, de su mundo, para ir afirmando el propio. Es una emancipación costosa, pautada por la lógica maduración personal pero también por los imperativos acontecimientos externos. Ello implica un cambio de tono, que transita de la jovialidad materna a la seriedad y a la angustia filial.

La madre posee una personalidad positiva, optimista, tolerante, confiada, es bien humorada, dicharachera, dinámica, de naturaleza alegre, coqueta, amante -especialmente de sus hijos y nietos, a los que cuida como una madre- y amada; había tenido una infancia risueña y era capaz de ser feliz, le gustaba la montaña y la naturaleza; estaba dedicada al cuidado de su casa y de su familia; era una mujer sociable, un poco caprichosa e inconstante, algo voluble, amiga de la poesía, la literatura, el teatro, el cine y la música. A menudo cantaba en casa retazos de ópera y de noche se reunía con sus hijos en torno a la mesa a recitar y a cantar. No había llegado a estudiar en la universidad, pero estaba interesada en aprender saberes nuevos. Sus hijas Paola y Natalia, educadas bajo su manto protector, completan la tríada femenina familiar.

El polo masculino, en contrapartida, lo componen el padre y sus tres hijos: Gino, Mario y Alberto. Todos ellos, con la excepción de Gino, compartían una vitalidad desbordante, un exceso de testosterona que llevaba en ocasiones al padre a intervenir a bofetada limpia en las violentas palizas que, como corolario de violentas discusiones, se propinaban entre sí sus hijos, hasta llegar a hacerse sangre, en medio del pánico de Lidia y Natalia. El señor Levi era un hombre honesto, sano (pero muy fumador, de pipa), risueño, deportista, impetuoso, apasionado, temerario, trabajador, culto, viajado, conocedor de idiomas, púdico, muy seguro de sí mismo, de criterios fijos, en ocasiones no muy práctico, bastante arbitrario, prepotente, con frecuencia rudo de formas, autoritario, pero tierno en el fondo, generoso y amante de su familia. Atormentaba a su esposa y a sus hijos, con su rigidez y sus excesos, pero Lidia lo amaba y Natalia lo admiraba y adoraba, como testimonia su presencia preeminente a lo largo del texto. Con todo, la mirada de la hija hacia su padre es equilibrada, ya que no oculta sus muchos excesos y defectos, que son un pilar de la comicidad de la obra ${ }^{15}$.

La emancipación de Natalia, pues, coincide con un avasallador transcurrir del tiempo. El tiempo es una categoría fundamental en este libro, que tanto trasiega con la memoria ${ }^{16}$. Eugenio Montale, en una reseña temprana y muy sutil, afirmaba: «Il tempo resta il grande assente della presente cronaca ${ }^{17}$. Es necesario matizar este juicio, que acaso haya distraído a la crítica, dada la gran autoridad de su autor, y reconducirlo a términos más precisos. Montale se refiere al transcurso temporal interno de la trama, pero también,

${ }^{15}$ Sobre Giuseppe Levi y su estatura científica se extiende su admirada y valiosa discípula Rita Levi-Montalcini (1989).

${ }^{16}$ «Lessico famigliare è un romanzo di pura, nuda, dichiarata e scoperta memoria» escribió su autora en la «Prefazione» a sus Cinque romanzi brevi e altri racconti (Ginzburg 1964: 17).

${ }^{17}$ Cfr. la nota 12. También Minghelli (1995: 167) se ha expresado en desacuerdo con dicha aseveración. 
desde luego, al tiempo histórico, que es el más trascendente. Y esto no es exacto. Vamos a comprobarlo:

La obra empieza con la frase «Nella mia casa paterna, quand'ero ragazzina», que ciertamente es una designación inconcreta, y acaba asimismo con una indeterminación temporal. Con todo, podemos contextualizar - a partir de datos externos- la niñez de Natalia en los primeros años veinte y también podemos identificar la cronología, aproximada, del final de la obra: En el último fragmento (46) surge una catarata de recuerdos verbalizados por Beppino y Lidia mientras se despiden de su hija Natalia, que dejará definitivamente Turín para instalarse en Roma. Son recuerdos con los que se entra en una dimensión cíclica, de repetición del pasado, como de clausura de un universo, el lector los reconoce bien ${ }^{18}$. Pero en los fragmentos que lo preceden, con todo, se citan algunos hechos que pueden ser fechados externamente y que nos hacen ver que la trama ha alcanzado ya los años cincuenta. A estos efectos son relevantes la mención de la muerte de Cesare Pavese, acaecida en 1950 (fragmento 41), y de la televisión, que la madre, Lidia, veía por las noches (40), pues la televisión existe en Italia desde 1954. Cierto es que el tiempo de la fábula, que incluye las historias recogidas de antepasados de la familia, se retrotrae por lo menos al siglo XIX.

La circularidad debida a las repeticiones consuetudinarias, ya había aparecido al principio del libro, ligada al citado tiempo mítico de la calle Pastrengo: «Passavamo sempre l'estate in montagna» (1), «Di solito in quelle villeggiature [...] ci veniva mia nonna» (2), «Lo yoghurt, in quegli anni, non era ancora di moda» (8), «In primavera crescevano nel nostro giardino, molte rose» (11). Y, en todo caso, en aquel tiempo, las cosas concretas que se recuerdan no están ligadas a una cronología precisa: «Un anno eravamo particolarmente senza soldi» (3),

«Un giorno [...] Galeotti era morto» (11),

«La Rina, dopo qualche settimana, tornava» (8),

«Una volta [...] un'altra volta» (13).

La excepción a estas generalidades, la constituye un tiempo detallado que no tiene que ver con la cronología exterior o histórica sino con los ritmos cotidianos, una medida interna que es mínima y que vuelve a marcar la repetición de los hábitos, de los que el padre era el guardián: «L'una era per mio padre 'il tocco', e il fatto che Alberto rientrasse 'dopo il tocco', gli sembrava una cosa inaudita» (13), «Mio padre tornava dal laboratorio alle sette e mezzo, e voleva trovarla [a su mujer] in casa quando tornava», si no se enfadaba (16).

\footnotetext{
${ }^{18}$ Desde luego, estos recuerdos lo son de los periclitados tiempos dichosos de la familia, pero, por otra parte, además de una despedida y un cierre -del libro, que genéricamente acaba como empezó-, pueden interpretarse como un augurio simbólico de tiempos mejores, más felices, por fin, para Natalia, con su nuevo marido, en la que va a ser su nueva ciudad, Roma. Como queriendo decir que quizás ella, con su marido y con sus hijos, pueda fundar su nuevo léxico familiar. Carlo Prosperi expone atinadas observaciones sobre el tiempo circular y las repeticiones del léxico familiar en el texto, fijándose a la vez en los tiempos verbales empleados por el narrador. Las repeticiones tendrían la finalidad de introducir a un extraño, el lector, en la globalidad del universo familiar y mantenerlo así en vida, ligándolo a esa especie de cantilena que queda en la memoria. El tiempo circular, por su parte, tras la guerra se convierte en una vana ilusión, el «idilio» se ha roto y ya no se puede recuperar (Prosperi 1996: 64-69).
} 
Es decir, que hasta aquí, sí es cierta la ahistoricidad del Lessico, como da a entender Montale. Y aún lo seguirá siendo para unos cuantos fragmentos más. Superados los que forman la primera parte, entrando ya en la siguiente, pese a que permanece la citada indeterminación («Adriano rimase nascosto da noi per diversi mesi», 17), empiezan a aumentar las referencias a una cronología algo más precisa -«A Palermo, a Palermo!, a Palermo era quindici anni fa» (18)-, aunque solo sea a veces en términos de efemérides familiares: «Avevamo cambiato casa» (16) o «Morí mia nonna» (18). Precisamente en el fragmento 16, que inaugura la segunda parte de la obra (que se extiende hasta el 31, antes de la guerra), el lector asiste al sucederse de una serie de hechos encadenados de ámbito intrafamiliar, relatados como un torbellino, cuyo efecto inmediato es enfatizar precisamente el transcurso del tiempo, esto es, subrayar que todo había cambiado: «Adesso anche noi avevamo il telefono [...] Gino abitava con sua moglie a Ivrea; Mario aveva un impiego a Genova [...] Alberto era stato messo [...] in collegio: [...] Mio padre non andava più a skiare: diceva che era diventato troppo vecchio. [...] Era morta Anna Kuliscioff. [...] I Terni dovevano lasciare Torino». Y sigue teniendo razón Montale.

Sin embargo, se llega a un punto en que las cosas empiezan a cambiar. Lo que más interesa es comprobar cómo la dimensión íntima del tiempo, que sustancialmente se refleja en esa imprecisión cronológica hasta ahora dominante, según acabamos de ver, acaba por imbricarse, a la fuerza, con el tiempo externo o histórico hasta casi fundirse y ser dominado por él. Y es que los hechos externos empiezan a prevalecer en la familia, expropiándola de su bienestar y de su antigua paz. El fascismo aprieta, con la represión, la cárcel y la guerra, que se imponen a todos, imparables. Y la cronología paulatinamente se va precisando más:

Mio padre rimase in carcere, mi sembra, quindici o venti giorni (19). Sion Segre e Ginzburg furono processati al Tribunale Speciale e condannati uno a due anni, l'altro a quattro; la pena fu però dimezzata, per una amnistia (19). Un anno dopo vennero a casa ad arrestare Alberto (...) vennero al mattino presto: erano forse le sei (20). Mio padre rimase nel Belgio due anni [confinado] (31). I miei primi due bambini nacquero, a un anno di distanza l'uno dall'altro, nel tempo che mio padre era in Belgio (31). Lo arrestarono, [a Leone] venti giorni dopo il nostro arrivo; e non lo rividi mai più (36).

La situación es tal que, cada vez más, las fechas se deducen por los hechos externos, de naturaleza política, militar o bélica: «Era morto in Spagna, in combattimento, il figlio di Giua» (27), se refiere a las Brigadas Internacionales, a las que el joven perteneció, que comenzaron a intervenir en los meses de noviembre-diciembre de 1936. «E la balia arrivò, ma proprio nei giorni che i tedeschi avevano invaso il Belgio» (31), esto es, en mayo de 1940. «Anche i genitori di Adriano [Olivetti] erano morti (...) proprio nei mesi che erano seguiti al armistizio», a saber, con posterioridad al 8 de septiembre de 1943 (40). «Vittorio [Foa] era uscito dal carcere durante il governo Badoglio» (40), o sea, entre julio de 1943 y junio de 1944. «erano stati uccisi, a Bagnole de l'Orne, i fratelli Rosselli» (28), lo que sucedió el 7 de mayo de 1937. «Cominció in Italia la campagna raziale» (29), lo que acaeció en la segunda mitad de 1938 (la correspondiente ley es de septiembre). «Mussolini dichiaró la guerra» (32), lo que ocurrió el 10 de junio de 1940. «Poi venne l'armistizio [...] e poi, due giorni dopo i tedeschi» (36). 
Los cuatro últimos ejemplos contienen hechos que incluso pueden aparecer desligados del estricto acontecer familiar, aunque son tan decisivos para la vida de todos que la narradora no puede dejar de citarlos. Pero Natalia también conserva en su memoria recuerdos personales cuya datación está vinculada con algunos hechos de ese tenor: «Io non li avevo mai rivisti tutti e tre insieme, Leone e l'editore e Pavese, dopo quella primavera che i tedeschi prendevano la Francia [1940], se non una sola volta, che eravamo venuti Leone e io dal confino dove l'avevano mandato subito dopo che era entrata in guerra l'Italia» [10/junio/1940] (35). «Gli avevano chiesto [a Giuseppe Levi] di mettere il suo nome nella lista dei candidati al Fronte popolare» (43), esto es, en 1948. Algunos de esos recuerdos son privados, intimísimos, inolvidables y por ello Natalia tiene bien presentes las fechas:

Quando nacque mia figlia Alessandra [...] Era l'estate del '43 [...] furono gli ultimi mesi che passavamo insieme Leone e io (36). Venne poi il 25 luglio, [de 1943, deposición de Mussolini] e Leone lasciò il confino e andò a Roma (36). Partii dal paese il primo di noviembre [de 1943, en Abruzzo, cuando huye por miedo a los nazis] (36). Leone era morto in carcere [...] a Roma, durante l'occupazione tedesca, un gelido febbraio [de 1944] (35). Apparivano tutt'e due invecchiati, mio padre e mia madre, alla fine della guerra [abril de 1945] (37).

De este modo hemos comprobado la presencia y la relevancia del tiempo (histórico) dentro del Lessico. Ahora bien, la autora se ha expresado a su estilo y con su técnica. Ha rehuido la declaración explícita, que inevitablemente dramatiza y solemniza, y, fiel a su crónica interior, ha luchado a su manera contra el avasallamiento de lo externo, pero no ha podido eludir su omnipotencia y solo ha alcanzado a atenuarla hasta cierto punto, empleando fórmulas perifrásticas y expresiones implícitas de una cronología portadora de los apabullantes hechos del fascismo y de la guerra, que a todos les cambiaron la vida. Pero las fechas están. El lector informado sabrá descifrar esa cronología que aparece cifrada en acontecimientos históricos, reconocerla y trascenderla. Las especificaciones temporales del Lessico, por otra parte, como hemos visto, no se extienden a la totalidad la obra sino principalmente a los años candentes del fascismo y la guerra, los peores ${ }^{19}$.

La cita de la muerte de Leone Ginzburg, un acontecimiento tan dramático y trascendente para Natalia, no está glosada por párrafo alguno que exprese el indudable dolor, si no la desesperación, de una viuda joven con tres hijos que amaba a su marido ${ }^{20}$.

\footnotetext{
${ }^{19}$ Sin llegar a profundizar detalladamente en su estudio, Carlo Prosperi sí tiene en cuenta el fenómeno del tiempo histórico en el L.F. y detecta «l'impatto violento con il tempo della storia» [por Historia] que se deriva del estallido de la guerra (Prosperi, 1996:68).

${ }^{20}$ Más adelante la autora escribiría: «M’è accaduto di conoscere bene il dolore dopo quel tempo che stavo nel sud, un dolore vero, irrimediabile e immedicabile, che ha spezzato tutta la mia vita e quando ho provato a rimetterla insieme in qualche modo, ho visto che io e la mia vita eravamo diventati qualcosa d'irriconoscibile rispetto a prima» («Il mio mestiere», en Ginzburg 1999: 204). En una jugosa y penetrante entrevista de la época, realizada por Oriana Fallaci, Natalia Ginzburg se extiende en algunos detalles de la muerte de Leone, por tortura, en la sección alemana de la cárcel de Regina Coeli (Fallaci 2009).

${ }^{21}$ Una importante y emotiva carta de Leone desde la prisión de Regina Coeli está recogida en el volumen Lettere di condannati a morte della resistenza italiana (Ginzburg 1999: 47). El editor Giulio Einaudi se extiende sobre la figura de Leone y su vínculo con la editorial -amén de sobre la historia de la editorial mismaen la entrevista Colloquio con Giulio Einaudi (Cesari, 2007).
} 
Incluso la comunicación de esta principal pérdida se le presenta al lector inopinadamente hacia el final de un fragmento no breve (el 35) dedicado a la editorial Einaudi y a su nueva organización ya en la inmediata posguerra ${ }^{21}$. Tras extenderse sobre Pavese, Einaudi y Balbo, se nos informa de que el primero de ellos había colgado un retrato de Ginzburg, de quien se nos transmite, lacónicamente, que había fallecido en los términos recién $\operatorname{citados}^{22}$.

Este es el ejemplo máximo de ese carácter reservado a ultranza de la narradora al que hemos aludido más arriba. Tal vez por ello, o tal vez por no rendirse y atribuirle todo el protagonismo en la vida familiar, la guerra está planteada en el texto en los términos de una matizada elipsis. Llama la atención que se la liquide en dos de los fragmentos más breves del libro, el 32 y el 33. El primero de ellos trata de la entrada en guerra y se recoge la expresión ya reproducida «Mussolini dichiarò la guerra» y el segundo da cuenta de la dimensión social cotidiana del fenómeno: al principio, en los primeros años, casi invisible para muchos y después arrolladora y destructiva para todos. Pero sin más detalles. No obstante, durante la guerra han sucedido eventos demasiado graves que no pueden ser omitidos, de ahí que posteriormente, en el fragmento 35 (como acabamos de ver, con Ginzburg) y, sobre todo, en el 36, del que ya hemos reproducido algunas frases, se comuniquen las informaciones más determinantes sobre ella y sus padres durante ese período. Es uno de los muchos casos de analepsis que jalonan el texto, como también los de prolepsis. En el fragmento 36 está contenido el relato de una de las situaciones más dramáticas, casi épicas, a las que tuvo que hacer frente, prácticamente sola, Natalia, como fue la huida con los niños del pueblo en el que estaban desterrados cuando los nazis invadieron Italia ${ }^{23}$. Otra es la posterior escapada del piso de Roma al sospechar -certeramente- que su marido había sido detenido por los nazis y a continuación podían caer prisioneros ella y sus hijos (ya en el fragmento 40).

Hay que destacar que incluso en alguno de los momentos más duros, el señor y la señora Levi conservan rasgos de humor e ironía o se producen situaciones ligadas a su idiosincrasia que al lector no pueden menos que resultarle (tragi)cómicas. Así, cuando la policía irrumpe temprano en la casa de la familia y se va a llevar detenido a Alberto, su madre, temerosa de posibles perquisiciones, desliza dentro de la cartera de Natalia, que se va a ir al colegio, los sobres con sus cuentas domésticas por miedo a que cayesen en manos de su marido, se descubrieran sus dispendios y él la riñese (20). O cuando a Giuseppe Levi, que estaba refugiado en el campo, cerca de Ivrea, bajo la identidad, falsa, de Giuseppe Lovisato una sirvienta le preguntaba a quién debía anunciar, y «Lui diceva però il suo vero nombre, diceva: - Levi. No, via, cioè, Lovisato» (36). O las veces en que Lidia, en una Florencia escasa de víveres, a los postres, daba a los tres hijos de Natalia, sus nietos, una manzana, porque no tenía más, menos si cabe para los otros comensales, y recitaba con naturalidad: «Ai piccoli una mela, ai grandi il diavolo che li pela. E raccontava

\footnotetext{
${ }^{22}$ Análogamente, la noticia de su segundo matrimonio la dará tarde y, de nuevo, de pasada: «Gabriele, mio marito, mi scriveva da Roma che mi sbrigassi a venir giù coi bambini» (45). Y casi de la misma manera había dado la del primero, abruptamente, sin aludir ni quiera al noviazgo, o a la actitud de su padre, como hace con los enlaces de sus hermanos: «Ci sposammo, Leone e io» (26).

${ }^{23}$ Casi cincuenta años después, al evocar el terror vivido y la ayuda recibida por los campesinos locales, se emociona y llora (Ginzburg 1999: 56).
} 
della Grassi che nell'altra guerra, ogni sera, prenderà una noce e la divideva in quatro: Una noce Lidia! - e ne dava uno spicchio ciascuno ai suoi quattro figli» (36).

Pasajes como estos, dramáticos pero a la vez sutilmente emotivos, iluminan el calado profundo del libro y nos obligan a precisar mejor las dimensiones del «léxico familiar», cuyo concepto hay que revisar y redefinir. Porque, superada la primera parte de la obra, cuando nos hallamos ya en los años más duros del fascismo, de la guerra y la posguerra, nos damos cuenta de que el léxico familiar excede con mucho a las meras frases graciosas y entrañables que actualizan o rememoran el pasado familiar común y se convierten en un arma compartida de resistencia a las desgracias del destino y a los zarpazos de la Historia, con sus plagas de autoritarismo y violencia. $\mathrm{O}$ al menos así lo hace ver la narradora. Y se evidencia que el léxico familiar además del citado patrimonio oral, sobre todo, comprende una actitud ante la sociedad y la vida, paciente y serena, incluso irónica, a veces; una educación recibida, un patrimonio que se hereda y transmite en familia, como preciado bagaje ético ${ }^{24}$. Y la narradora, más allá de que como personaje está igualmente afecta, se sirve de ese patrimonio -que para el lector con frecuencia no deja de tener su vis cómica- para entreverar el relato de los mil sufrimientos familiares en los años difíciles ${ }^{25}$.

Es decir, que ese mismo léxico que entendemos, pues, en un sentido ya más amplio como comprensivo de costumbres, actitudes, decisiones, etc. cambia de función estructural. Y si en la primera parte provocaba la risa, como cúmulo de curiosidades y excentricidades, después es también un contrapunto, un hilo conductor familiar que alivia al lector y sirve de ventilación en el universo claustrofóbico, angustioso y represor del fascismo y la guerra. Y un testimonio de que los Levi no se dejan arrastrar fácilmente por las adversidades.

Hemos hablado más arriba de un movimiento de emancipación progresiva de Natalia respecto de la influencia materna, que se desarrolla hasta afirmar su propio mundo. Pero en verdad, de fondo, la influencia vital -que no discursiva- paterna debía ser tan fuerte como la materna, aunque menos visible en la superficie de los hábitos. A pesar de las muchas indecisiones en los asuntos prácticos, Natalia era exigente con los demás y determinada de carácter, incluso acaso obstinada, como el señor Levi; no por casualidad, ya de niña la llamaba su madre unas veces «Maria Temporala» (10), apelativo que heredará su hija Alessandra (40), y otras «la mia padrona» (17). La emancipación del personaje discurre paralela a la de la voz narradora. Y la narradora crece y madura con el personaje. Hay un abismo entre la niña que reconocía a Filippo Turati, el líder socialista, refugiado clandestino en su casa, y por obedecer a sus padres, aceptaba cándidamente llamarlo Paolo Ferrari y creía que era a la vez el uno y el otro (17), como nos explica casi

\footnotetext{
${ }^{24}$ Giovanelli (2005: 740) se expresa, a este respecto, en términos de «coesione amicale o familiare». Es otro matiz.

${ }^{25}$ Minghelli (1995: 163), por su parte, afirma que «L'affabulazione della madre esercita un potere esorcistico sul mondo. Durante i lunghi anni del fascismo e la tragedia dell'ocupazione [...] [las expresiones del léxico familiar] agiscono come incantesimi, formule magiche che attraverso la ripetizione cercano di allontanare il male, dissipare le minacce che incombono sul fragile tessuto della comunità».

${ }^{26}$ Más adelante la narradora -identificada con la niña- escribirá «Paolo Ferrari rimase in casa nostra» (17), dando por bueno el nombre falso.
} 
con ingenua naturalidad la narradora ${ }^{26}$, y la cronista casi puntillosa de sus amigos, adultos, especialmente, por ejemplo, de los Balbo o del mismo Pavese.

Si en las primeras partes del libro es cierto que Natalia recrea el ambiente vivaz, alegre y colorista de su casa -que incluye a sus padres y hermanos y a las sirvientas y amigos y otros parientes de la familia-, con la llegada de la posguerra surge una voz narrativa con matices distintos. Hay una evolución. Es una voz distinta que cuenta una historia que se ha transformado mucho. Ya no hay todo aquel ajetreo de la calle Pastrengo, apenas ve a sus hermanos, sus padres se han hecho mayores y otros personajes van ocupando la vida de Natalia. Ha perdido a Leone, es una joven viuda, sobrevive como puede, se apoya mucho en su madre para el cuidado de los niños y casi todos los amigos los recaba del mundo de la Einaudi, donde trabaja. Hay un pesimismo larvado y una tristeza que asoma en no pocas ocasiones, un dolor no exhibido pero que el lector acierta a imaginar, un sufrimiento que ha de ser intenso, cercano a la desesperación. Y en estas circunstancias su universo está más concentrado, ya no hay aquel ir y venir de tantos personajes e historias. Y a los Balbo, Filippo y Lola, les dedica muchas páginas llenas de pormenores, en las que asoma la ironía y la distancia de antes pero con nuevas aristas de crítica, a veces incluso acerba.

Junto con Lisetta o Pavese, esa familia conforma el grupo de los amigos de la nueva etapa y representa ya algo distinto a lo que fue la familia Levi. Aunque en casa de los Levi también había mucha algarabía y muchas querellas, el matrimonio de Beppino y Lidia estaba muy bien asentado y tenía una gran complementariedad. No es este el caso de los Balbo, como tampoco lo es, desde luego, el de Mario y Paola, los hermanos de Natalia, que se han divorciado de sus respectivos cónyuges y han encontrado nuevas parejas, incluso teniendo Paola ya hijos de la primera. Es decir, se nos hace ver que ya la generación siguiente, la de los hijos, es diferente a la de los padres (también los Lopez y los Terni, amigos de los Levi, eran familias muy bien avenidas), que nuevos tiempos se están afirmando; la misma Natalia volverá a casarse, aunque en otras circunstancias, por supuesto. Se está abriendo, muy sutilmente, el camino hacia otros modelos de familia, o más bien hacia la descomposición del anterior, que es lo que ocupará el quehacer narrativo de los años futuros de Ginzburg, cuya insignia puede ser Caro Michele, la novela epistolar de 1973.

Y a través de la descripción de estos amigos Natalia, sin renunciar a su parquedad autobiográfica, comunica nuevos retazos sobre sí misma, o deja que el lector avezado los deduzca. Así, cuando leemos que Lola Balbo, «non sapeva tanto bene far da madre, essendo passata dalle nebbie dell'adolescenza all'intemperie della vita adulta» (41) se nos transparenta la propia biografía de Natalia. O a propósito de la amiga común Lisetta, sabemos que las tres se pusieron a estudiar ruso, pero que la Ginzburg acabó dejándolo. O cuando asevera que Lisetta, en relación con desavenencias ideológicas, no era capaz de confesarse a sí misma: «son miei amici e gli voglio bene e non me ne importa niente se le loro opinioni siano vere o false» (41) también estamos asistiendo a la exposición de una norma de su propia conducta. La pertenencia de Natalia al Partido Comunista sale a relucir, de pasada, porque Balbo le recomendaba combatir su melancolía asistiendo más activamente a las reuniones de célula o de sección (41). Y también en la compañía de los Balbo recuerda cuando se estilaba «fare l'autocrítica» entre ellos (43). Y su silencio sobre su actividad de traductora queda discretamente roto: «Quando esce la tua traduzione 
di Proust? - mi diceva mia madre» (44).

Ella, Natalia, es la guía de este libro pero también acaso su mayor misterio. Podemos creer que lo que cuenta sustancialmente corresponde a su visión honesta de las cosas, pero lo que no sabemos es lo que no cuenta. Lessico famigliare es una crónica parcelada llena de mil historias que abarca dos posguerras, la del primer y el segundo conflicto mundial, esos son sus límites cronológicos. En ella la niña pequeña de la casa, última distanciada después de cuatro hermanos, postergada en el seno de una familia de adultos ${ }^{27}$, donde se llama «Natalina» a la sirvienta y Natalia a la hija, recrea el ambiente del hogar y su posterior evolución. No oculta sus celos hacia su hermana Paola ni deja de hacer notar las contradicciones y absurdos de muchos comportamientos ajenos, incluidos los de su madre y otros miembros de la familia. El aire es el de una sinceridad muy convincente, pues tampoco deja de reconocer algunas carencias y límites personales, pero, en línea con lo que afirmaba su amigo Garboli, tal vez, haya algo de simbólico ajuste de cuentas en este libro, de escribir la historia recolocando a sus personajes hasta componer su propio teatro. Pero, ¿podría ser sustancialmente de otra manera? ${ }^{28}$.

\section{REFERENCIAS BIBLIOGRÁFICAS}

GINZBURG, Natalia (1964): «Prefazione» a Cinque romanzi brevi e altri racconti. Torino, Einaudi.

GINZBURG, Natalia (1986-1987): Opere raccolte e ordinate dall'Autore. Prefazione di Cesare Garboli, Milano, Arnoldo Mondadori, 2 vols. (I Meridiani).

GinZBURG, Natalia (1999): È difficile parlare di sé. Conversazioni a più voci condotta da Marino Sinibaldi. A cura di Cesare Garboli e Lisa Ginzburg. Torino, Einaudi.

AA.VV. (1986): Natalia Ginzburg. La narratrice e $i$ suoi testi. Roma, La nuova Italia Scientifica.

BARANI, Valeria (1990): «Il 'latino’ polifonico della famiglia Levi nel Lessico famigliare di Natalia Ginzburg», Otto/Novecento 6, pp. 147-157.

Cesari, Severino ([1991] 2007): Colloquio con Giulio Einaudi. Torino, Einaudi.

CoBurn, Melissa (2007): «Resistance-at-risk: The Critique of Fascim and Ethics of Writing in Natalia Ginzburg's Lessico famigliare», Italica 84: 4, pp. 755-769.

D’Ambrosio, Raffaella (2005): I personaggi del «Lessico famigliar» di Natalia Ginzburg. St. Gallen, Pädagogische Hochschule St.Gallen.

FALLACI, Oriana ([1963] 2009): «Con molto sentimento», en Gli antipatici. Milano, Rizzoli, (BUR, $1^{\text {a }}$ ed.), pp. 304-323.

GiovanelLI, Paola Daniela (2005): «Natalia Ginzburg: il silenzio, le pulci e lo specchio», en G. M. Anselmi et al. (eds.), Da Dante a Montale. Studi di filologia e critica letteraria in Onore di Emilio Pasquini. Bologna, Gedit Edizioni, pp. 733-748.

\footnotetext{
${ }^{27}$ «[...] mia madre e [...] i miei fratelli, che mi dicevano di star zitta. Quando parlavo mi dicevano di star zitta» (Ginzburg 1999: 75).

${ }^{28}$ La identificación autor-narrador (-protagonista) a la que hemos aludido no puede ser completamente compacta: sin duda hay fisuras. Lo acabamos de ver. Es un campo de estudio que se presta a la aplicación, entre otras, de metodologías de análisis psicologistas y también a las propias de la escritura del yo mencionadas en la nota 6.
} 
GONZÁLEZ FERNÁNDEZ, Isabel (1996): «Distintos niveles de lengua en Lessico famigliare de Natalia Ginzburg», en F. Díaz Padilla (ed.), Il Novecento. Actas del V Congreso Nacional de Italianistas Españoles. Oviedo, Universidad de Oviedo, pp. 255-266.

IoLI, Giovanna (ed.) (1996): Natalia Ginzburg: la casa, la città, la storia. Atti del Convegno Internazionale. San Salvatore Monferrato, 14-15 maggio 1993. San Salvatore Monferrato, Barberis.

LEJEUnE, Philippe (1996): El pacto autobiográfico y otros estudios, Madrid, Mezagul, Endymion.

LeVi-Montalcini, Rita (1989): Elogio de la imperfección, Barcelona, Ediciones B.

MAgRINI, Giacomo (2007): «Lessico famigliare di Natalia Ginzburg», en A. Asor Rosa (dir.), Letteratura italiana. Vol. 17. Il secondo Novecento. Le opere dal 1962 ai giorni nostri. Torino, Einaudi / La Repubblica-L'Espresso, pp. 59-116.

Mangoni, Luisa (1999): Pensare i libri. La casa editrice Einaudi dagli anni trenta agli anni sessanta, Torino, Bollati Boringhieri.

Minghelli, Giuliana (1995): «Ricordando il quotidiano. Lessico famigliare o l'arte del cantastorie», Italica 72: 2, pp. 155-173.

PARISI, Luciano (2002): «I romanzi di Natalia Ginzburg», Quaderni d'Italianistica vol. XXIII, no 2 , pp. 107-120.

PROSPERI, Carlo (1996): «Il linguaggio della tribù: una lettura di Lessico famigliare di Natalia Ginzburg», en G. Ioli (ed.), pp. 59-74.

QuARsiti, Maria Luisa (1996): Natalia Ginzburg: bibliografia 1934-1992. Firenze, Giunti. 